\title{
Premating and gestational effects of maternal nutrition on secondary sex ratio in house mice
}

\author{
D. B. Meikle* and M. W. Thornton \\ Department of Biology, Hood College, Frederick, Maryland 21701, USA
}

\begin{abstract}
Pregnant female house mice maintained on a consistent low-food diet give birth to a lower proportion of males than do control females fed ad libitum. Because house mice may experience daily fluctuations in food availability, we tested whether intermittent feeding during gestation influences the sex ratio of the offspring. In addition, we tested whether intermittent feeding has asymmetrical effects on the masses of adult male and female offspring. Females deprived of food every other day one week before mating and those deprived every third day during gestation produced a lower proportion of males than did control (fed ad libitum) females. Males born to females that were deprived of food during gestation had the same body mass at birth as males born to control females, but as adults their mass was lower than that of control males. There were no differences in the birth or adult body masses of female offspring. Because males of low body mass may have relatively low lifetime reproduction, our results support the Trivers-Willard model of sex ratio variation.
\end{abstract}

\section{Introduction}

In many polygynous mammals, males compete for access to mates and usually suffer higher mortality than do females (Clutton-Brock, 1988). Males also vary in their success at being chosen as mates (Kirkpatrick, 1982; Wolff, 1985; Meikle et al., 1995). As a result, males typically have higher variance in lifetime reproductive success (LRS) than do females (CluttonBrock, 1988). Trivers and Willard (1973) argued that in such species, females in poor condition are likely to produce offspring that are in poor condition, and those offspring are apt to have lower LRS than are the offspring of females in good condition. They hypothesized that the LRS of male offspring would be influenced more strongly by maternal condition than that of female offspring, because females usually do not compete for mates, suffer as high mortality as males, or show as large a variance in their LRS. The reproductive potential of males born to females in poor condition is likely to be lower than that of female offspring and vice versa for male and female offspring of females in good condition. Hence, Trivers and Willard (1973) predicted that females in poor condition should give birth to a lower proportion of male offspring, and the reverse for females in good condition (reviewed by Clutton-Brock and lason, 1986).

Females of many rodents give birth to a lower proportion of males if they are maintained on a low fat (Rivers and Crawford, 1974) or low calorie diet (Labov et al., 1986; Wright et al., 1988), rather than fed ad libitum. For example, Wright $e t$ al. (1988) reported that albino female house mice fed only $65 \%$ of the food mass they consumed when food was available ad libitum produced a much lower proportion of males and fewer

*Present address: Department of Biology, Appalachian State University, Boone, NC 28608, USA.

Received 24 March 1995. offspring than did females fed ad libitum. In addition, the males born to low-food females were significantly heavier than those born to well-fed females.

In the above studies, females were fed a restricted diet on a daily basis throughout the period of gestation. Meikle and Drickamer (1986) argued that large fluctuations in food availability may occur for species like house mice (Jakobson, 1981; Ward, 1981; Bronson, 1985). Rather than maintaining females on a steady low calorie diet, they deprived females of food intermittently. They found that females deprived of food every other day for one week before mating, but fed ad libitum during gestation, produced a lower proportion of males than did control females. However, it is not known whether intermittent food deprivation during gestation has similar effects on offspring sex ratio, litter size and pup masses, as a consistent low-food diet. We therefore compared females that were deprived of food intermittently during gestation with control females that were fed ad libitum. A third group of females was deprived of food every other day one week before mating in order to compare the results to earlier experiments by Meikle and Drickamer (1986).

The Trivers and Willard (1973) model predicts that males born to mothers in poor condition will be in poor condition relative to those born to mothers in good condition, but that there should not be as large a difference in the condition of female offspring. Hence, we raised male and female offspring of our deprived and control females to maturity to see whether maternal nutrition before or during gestation affected the body mass of adult offspring (Labov et al., 1986; Huck et al., 1988; Krackow, 1993).

\section{Materials and Methods}

\section{Animals}

Albino mice (CF1 strain, Harlan-Sprague-Dawley, Inc.) were used because they show a sex ratio response identical to 
Table 1. Offspring sex ratios, mean litter sizes, and fertility of control, premating and gestation food-deprived female house mice

\begin{tabular}{lcccccc}
\hline Treatment & $\begin{array}{c}\text { Proportion } \\
\text { of males }\end{array}$ & Male & $\begin{array}{c}\text { Sex bias of litter: } \\
\text { Female }\end{array}$ & Equal & $\begin{array}{c}\text { Mean } \\
\text { litter } \\
\text { size }\end{array}$ & $\begin{array}{c}\text { Fertility } \\
(\%)\end{array}$ \\
\hline Control & 0.55 & 11 & 3 & 2 & $10.1^{\mathrm{a}}$ & $16 / 24(0.67)^{\mathrm{c}}$ \\
Premating & 0.42 & 3 & 14 & 6 & $12.6^{\mathrm{ab}}$ & $23 / 24(0.96)^{\mathrm{cd}}$ \\
Gestation & 0.44 & 4 & 9 & 3 & $8.2^{\mathrm{b}}$ & $17 / 24(0.71)^{\mathrm{d} *}$ \\
\hline
\end{tabular}

aLeast significant difference $P<0.05$.

'Least significant difference $P<0.01$.

$\chi^{2}=6.7 . \mathrm{df}=1, P<0.01$.

${ }^{d} \chi^{2}=5.4, \mathrm{df}=1, P<0.02$.

* Sexes not determined for one litter.

that of wild Mus musculus (Meikle and Drickamer, 1986; Drickamer and Meikle, 1988; Wright et al., 1988). Each of 72 adult ( $>60$ days) virgin females was randomly assigned to one of three groups: premating deprived ('premating'), gestation deprived ('gestation'), and fed ad libitum ('control'). Females were housed individually in opaque polypropylene cages $(15 \mathrm{~cm} \times 28 \mathrm{~cm} \times 15 \mathrm{~cm})$ for 3 weeks before the experiment. The colony rooms were maintained at $21-23^{\circ} \mathrm{C}$ and $30-70 \%$ relative humidity with lights on from $06: 00 \mathrm{~h}$ to $20: 00 \mathrm{~h}$. Purina $5015^{\text {Ni }}$ mouse chow was available ad libitum to all mice before the start of the experiments, and water was available ad libitum to all mice throughout the experiments.

\section{Feeding protocol}

Control females were fed ad libitum at all times. Premating females were deprived of food every other day for one week before mating (fed ad libitum on alternate days), for a total of four 1 day periods without food. Premating females were then fed ad libitum for the duration of the experiment. At that point, a randomly chosen adult CF1 male was added to each female's cage in all three groups. After 10 days, the males were removed and the gestation females were begun on their deprivation schedule. Previous experiments (Drickamer and Meikle, 1988) showed that females deprived of food every other day during gestation rarely produced a litter. Hence, gestation females were deprived every third day for 12 days (ad libitum on the intervening two days), and then fed ad libitum thereafter. Each premating and gestation female was therefore subjected to four $24 \mathrm{~h}$ periods without food. This schedule of mild food deprivation did not have serious negative effects on females, and there were no deaths.

\section{Body masses of offspring}

Control females were weighed each day; premating females were weighed every day before the introduction of males; and gestation females were weighed every day after removal of males. The sex of each pup was determined at birth and all pups were weighed. At weaning, two male and two female offspring, randomly chosen, from each litter were weighed at 90 days of age.

\section{Statistical analyses}

All statistical tests and probabilities were taken from Sokal and Rohlf (1995) and Rohlf and Sokal (1995). Bartlett's test for homogeneity of variances was used to determine whether datasets were homoscedastic (all $P$ values $>0.05$ ). Differences among means were tested for control, premating and gestation groups with one-way analysis of variance (ANOVA). Multiple comparisons between means were made using the least significant difference procedure. A chi-squared test was used to test for independence between maternal treatments and secondary sex ratios, as well as the numbers of females producing a litter. Pearson's correlation coefficient was used to test for associations between variables. Linear regression analysis was used to compare the rates of weight gain during gestation.

\section{Results}

\section{Offspring sex ratios}

Premating and gestation females gave birth to a lower proportion of males than did control females (assuming each birth was an independent event, $\chi^{2}=7.66, \mathrm{df}=2, P<0.025$; Table 1). Premating and gestation mothers also produced more female-biased than male-biased litters, while control mothers produced more male-biased than female-biased litters $\left(\chi^{2}=14.12, \mathrm{df}=4, P<0.01\right.$; Table 1$)$. There was no correlation between the proportion of males born and maternal body mass before treatment (Pearson $r$, all $P$ values $>0.2$ ) or just after birth (all $P$ values $>0.2$ ).

\section{Body masses of offspring}

There were no differences in the mean body masses at birth of female or male pups among the three treatments (female $F_{2.53}=1.06, P>0.2$; male $F_{2,53}=0.82, P>0.1$; Table 2). In addition, there were no differences in the adult ( 90 days of age) masses of female offspring $\left(F_{2,28}=0.634, P>0.2\right)$. However, there were significant differences in the body masses of adult males $\left(F_{2.35}=6.58, P<0.005\right)$. The mean body mass of adult males born to control females was greater than that for males 
Table 2. Mean body mass $(\mathrm{g})$ before treatment and at birth for female house mice that produced litters and mean body mass of offspring at birth and at 90 days

\begin{tabular}{|c|c|c|c|c|c|c|}
\hline \multirow[b]{3}{*}{ Treatment } & \multicolumn{2}{|c|}{ Mothers } & \multicolumn{4}{|c|}{ Offspring } \\
\hline & \multirow{2}{*}{$\begin{array}{c}\bar{x} \text { initial } \\
\text { mass }\end{array}$} & \multirow{2}{*}{$\begin{array}{l}\bar{x} \text { mass at } \\
\text { parturition }\end{array}$} & \multicolumn{2}{|c|}{$\begin{array}{l}\overline{\mathrm{x}} \text { mass } \\
\text { at birth }\end{array}$} & \multicolumn{2}{|c|}{$\begin{array}{c}\bar{x} \text { mass } \\
\text { at } 90 \text { days }\end{array}$} \\
\hline & & & Male & Female & Male & Female \\
\hline Control & $27.3^{a}$ & $33.3^{\mathrm{b}}$ & 1.4 & 1.4 & $32.7^{\mathrm{cd}}$ & 24.8 \\
\hline Premating & $27.2^{a}$ & $34.2^{b}$ & 1.3 & 1.3 & $30.2^{c}$ & 25.0 \\
\hline Gestation & $26.0^{a}$ & $30.8^{b}$ & 1.3 & 1.3 & $30.1^{d}$ & 24.0 \\
\hline
\end{tabular}

${ }^{\mathrm{a}} F_{2.53}=6.13, P<0.005$.

${ }^{\mathrm{b}} F_{2,53}=14.36, P<0.001$

${ }^{c d}$ Least significant difference $P<0.01$.

born to either gestation or premating females (Table 2), but there was no difference in the body masses of males born to premating and gestation females.

\section{Maternal body masses}

The mean body mass of control females was stable through the premating period and increased steadily throughout the gestation period. Both premating and gestation females showed a consistent pattern of losing approximately $15 \%$ of body mass after $24 \mathrm{~h}$ without food, and regaining the lost mass after $24 \mathrm{~h}$ with ad libitum food. During gestation, the daily mean body mass of gestation females increased at a lower rate than that of control females (slopes $=1.56$ and 0.90 , respectively, $t=2.18, \mathrm{df}=18, P<0.05)$. There were no significant differences in the time to conceive among the three treatments. On average, control females gave birth 22 days after males had been introduced, while premating and gestation females gave birth at 22.8 and 23 days, respectively. Hence, deprivation of gestation females began on about day 8 of gestation.

The mean initial (pretreatment) body mass of gestation females that produced a litter was lower than that of control or premating females (Table 2). Likewise, the mean body mass at parturition of gestation females was lower than that of control or premating females (Table 2). However, there was no significant correlation between body mass and litter size for control (Pearson $r=0.14, P>0.2$ ) or gestation females $(r=0.267, P>0.2)$, but there was a trend among premating females $(r=0.40, P=0.06)$. Premating females produced larger litters than did gestation or control females $\left(F_{2,53}=15.96\right.$, $P<0.001$; Table 1). A larger proportion of premating females produced a litter compared with both control and gestation females, but there was no difference in the proportion of control and gestation females that produced litters (Table 1).

\section{Discussion}

In general, the results reported here support the Trivers and Willard (1973) model. The premating and gestation females, which were undernourished relative to control females, produced a lower proportion of males than did control females.
These sex ratio results parallel those reported by Meikle and Drickamer (1986), who found that female mice that were deprived of food before mating gave birth to a lower proportion of males than did control females. In addition, Wright et al. (1988) reported that females maintained at 65\% of ad libitum food levels before and during most of gestation produced a lower proportion of males than did control females.

Intermittent feeding of gestation females began 10 days after the introduction of males, and well into the gestation period of those females. This suggests that the reduced proportion of male offspring, and smaller litter sizes of gestation compared with control females, resulted from fetal resorption. Krackow (1992) reported that sex ratio variation in relation to parity and previous reproductive condition is primarily a function of fetal resorption. It is not clear what mechanism caused the skewed sex ratios of our premating females. Food deprivation of premating females may have had a carry-over effect into gestation, and the skewed offspring sex ratios of those females may have been caused by fetal resorption. However, this seems unlikely, because premating females had significantly larger litters than did females in the other treatments. The two most likely explanations are that premating females controlled whether $\mathrm{X}$ - or $\mathrm{Y}$-chromosome sperm fertilized their ova or that they conceived an excess of zygotes and skewed the sex ratio among those that implanted (Meikle et al., 1984).

It is not clear why premating females had higher fertility and produced larger litters than did gestation and control females. Meikle and Drickamer (1986) did not find that premating females had higher fertility or fecundity (litter size). Increased food availability is usually associated with greater fertility and fecundity (Bronson, 1989), but reduced food intake, followed by abundant food just before mating is often used to increase fertility and fecundity in the production of some domestic animals (Beltranena et al., 1991). Although the differences in timing of conception, or duration of gestation, were not significant, control females delivered their pups about one day earlier than did females in the other two groups. It is possible that this small difference caused the differences in fertility or fecundity through increased numbers of pseudopregnancies, or some other unknown mechanism. 
Our results also support the Trivers and Willard model because adult males born to control females weighed more than those born to premating and gestation females. Female golden hamsters that are underfed during gestation not only produce skewed sex ratios, as we observed, but their male offspring are also of lower mass than those of females fed ad libitum (Labov et al., 1986). The relatively low mass of adult males born to food-deprived mothers reduces the probability that they will establish and maintain a territory (Vessey, 1967; Krackow, 1993), and they may therefore have relatively low reproductive potential (Wolff, 1985). In addition, males of lower body mass are less attractive to females at oestrus than are heavier males (Meikle et al., 1995). Consistent with the Trivers and Willard model, we found no relationship between maternal treatment and the adult body mass of female offspring.

We do not know what mechanism may have caused the sex difference in adult body masses. There were no differences in the masses of male or female pups at birth, just after the period of intermittent feeding, and all animals were fed ad libitum after birth. Maternal nutrition-related variation in fetal plasma concentrations of insulin-like growth factors is one possible mechanism for the differences in body mass of the offspring (Kroonsberg et al., 1989). In addition, undernutrition disrupts steroidogenesis and the development of accessory sex glands in males (Sisk and Bronson, 1986; Bronson, 1989). Deprivation of females during gestation may have reduced nutrients received by their male fetuses during a critical period of sexual differentiation (Ward and Weisz, 1980), and reduced concentrations of testosterone or other androgens may have influenced the body mass of adult male offspring. Wright et al. (1988) reported that the mean body mass at birth of low-food intake male, but not female, pups was higher than that of control male pups, while we observed no effect of intermittent food availability on the masses of either sex at birth. However, both male and female offspring of females of low food intake in the study of Wright et al. (1988) were heavier than the controls at weaning. The difference in offspring masses reported here may be due to differences between the effects of intermittent feeding and of a constant low-food diet.

The results reported here, taken together with other evidence, suggest that the reduced proportion of males born to food-deprived mothers may be adaptive, as hypothesized by Trivers and Willard (1973). If males born to food-deprived mothers have lower body mass as adults, they may have lower lifetime reproductive success than do males born to well-fed mothers (Meikle et al., 1995). In addition, maternal effects are often greater for males than for females (Politch and Herrenkohl, 1984; Meikle and Drickamer, 1986; Labov et al., 1986; Krackow, 1993). If the male offspring of undernourished female house mice have lower reproductive potential than females, and vice versa for males and females of well-nourished females, then the ability of female mice to adjust the offspring sex ratio in response to their nutritional state may be adaptive.

This research was supported in part by the National Science Foundation (DEB-9317874) and the Hood College Board of Associates. The authors thank J. A. Bruseo, T. W. Carpenter, C. L. Hull, R. H. Lewellen, S. B. Meikle, and S. H. Vessey for helpful comments and suggestions.

\section{References}

Beltranena E, Foxcroft GR, Aherne FX and Kirkwood RN (1991) Endocrinology of nutritional flushing in gilts Canadian Journal of Animal Science 71 1063-1071

Bronson FH (1985) Mammalian reproduction: an ecological perspective Biology of Reproduction $321-26$

Bronson FH (1989) Mammalian Reproductive Biology University of Chicago Press, Chicago

Clutton-Brock TH (1988) Reproductive success. In Reproductive Success pp 472-485 Ed. TH Clutton-Brock. University of Chicago Press, Chicago

Clutton-Brock TH and Iason GR (1986) Sex ratio variation in mammals Quarterly Review of Biology 61 339-374.

Drickamer LC and Meikle DB (1988) Food deprivation affects reproduction in adult female mice (Mus musculus) and the age of puberty for their female progeny Acta Biologica, Hungarica 39 361-375

Huck UW, Pratt NC, Labov JB and Lisk RD (1988) Effects of age and parity on litter size and offspring sex ratio in golden hamsters (Mesocricetus auratus) Journal of Reproduction and Fertility 83 209-214

Jakobson ME (1981) Physiological adaptability: the response of the house mouse to variations in the environment Symposium Proceedings of the Zoological Society of London 47 301-335

Kirkpatrick M (1982) Sexual selection and the evolution of female choice Evolution 36 1-12

Krackow S (1992) Sex ratio manipulation in wild house mice: the effect of fetal reabsorption in relation to the mode of reproduction Biology of Reproduction $47541-548$

Krackow S (1993) The effect of weaning weight on offspring fitness in wild house mice (Mus musculus domesticus): a preliminary study Ethology 95 $76-82$

Kroonsberg C, McCutcheon SN, Siddiqui RA, Mackenzie DDS, Blair HT, Ormsby JE, Breier BH, and Gluckman PD (1989) Reproductive performance and fetal growth in female mice from lines divergently selected on the basis of IGF-I concentrations Journal of Reproduction and Fertility 87 349-353

Labov JB, Huck UW, Vaswani P and Lisk RD (1986) Sex ratio manipulation and decreased growth of male offspring of undernourished golden hamsters (Mesocricetus auratus) Behavioral Ecology and Sociobiology 18 241-249

Meikle DB and Drickamer LC (1986) Food availability and secondary sex ratio variation in wild and laboratory house mice (Mus musculus) Journal of Reproduction and Fertility 78 587-591

Meikle DB, Tilford BL and Vessey SH (1984) Dominance rank, secondary sex ratio, and reproduction of offspring in polygynous primates American Naturalist 124 173-188

Meikle DB, Kruper JH and Browning CR (1995) Adult male house mice born to undernourished mothers are unattractive to oestrous females Animal Behaviour 50 753-758

Politch JA and Herrenkohl LR (1984) Effects of prenatal stress on reproduction in male and female mice Physiology and Behavior 32 95-99

Rivers JPW and Crawford MA (1974) Maternal nutrition and sex ratio at birth Nature 252 297-298

Rohlf FJ and Sokal RR (1995) Statistical Tables WH Freeman and Co., New York

Sisk C and Bronson FH (1986) Effects of food restriction and restoration on gonadotropin and growth hormone secretion in immature male rats Biology of Reproduction 35 554-561

Sokal RR and Rohlf FJ (1995) Biometry WH Freeman and Co., New York

Trivers RL. and Willard DE (1973) Natural selection and parental ability to vary the sex ratio of offspring Science $17990-92$

Vessey SH (1967) Effects of chlorpromazine on aggression in a laboratory population of wild house mice Ecology 48 367-376

Ward RJ (1981) Diet and nutrition Symposium Proceedings of the Zoological Sociefy of London 47 255-266

Ward IL and Weisz J (1980) Maternal stress alters plasma testosterone in fetal males Science 207 328-329

Wolff RJ (1985) Mating behaviour and female choice: their relation to social structure in wild caught house mice (Mus musculus) housed in a semi-natural environment Zoology (A) 207 43-51

Wright SL, Crawford CB and Anderson JL (1988) Allocation of reproductive effort in Mus domesticus: responses of offspring sex ratio and quality to social density and food availability Behavioral Ecology and Sociobiology 23 357-365 